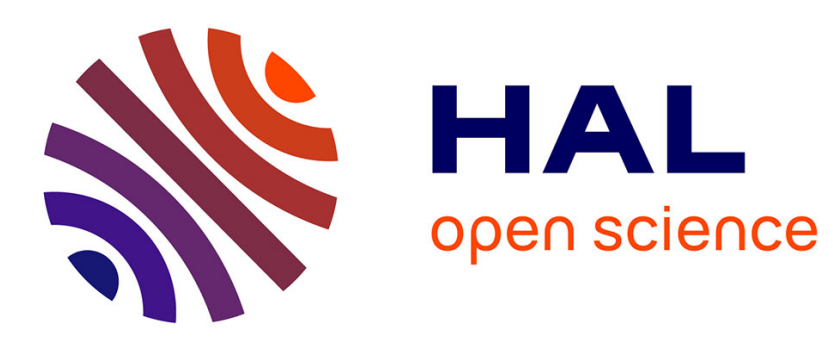

\title{
Pour répondre aux défis du XXIe siècle: la pensée d'Alfred Sauvy
}

Gérard-François Dumont

\section{To cite this version:}

Gérard-François Dumont. Pour répondre aux défis du XXIe siècle: la pensée d'Alfred Sauvy. Population et avenir, 2012, 708, pp.3. 10.3917/popav.708.0003 . halshs-00762818

\section{HAL Id: halshs-00762818 https://shs.hal.science/halshs-00762818}

Submitted on 8 Dec 2012

HAL is a multi-disciplinary open access archive for the deposit and dissemination of scientific research documents, whether they are published or not. The documents may come from teaching and research institutions in France or abroad, or from public or private research centers.
L'archive ouverte pluridisciplinaire HAL, est destinée au dépôt et à la diffusion de documents scientifiques de niveau recherche, publiés ou non, émanant des établissements d'enseignement et de recherche français ou étrangers, des laboratoires publics ou privés. 


\section{Pour répondre auX défis du XXI ${ }^{\mathrm{e}}$ siècle : la pensée d'Alfred Sauvy}

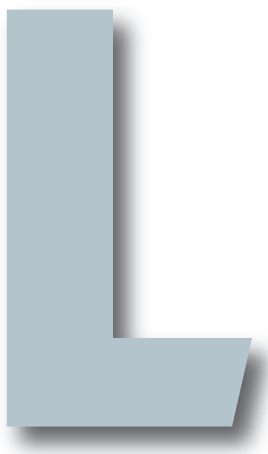

\section{par Gérard-François DUMONT}

e diagnostic de la France, à l'heure où débute un nouveau quinquennat présidentiel, n'indique pas un pays en santé éclatante. Ses atouts, qu'il s'agisse de la diversité de ses territoires ou de ses multiples innovateurs locaux, sont souvent méconnus, mésestimés, voire même parfois jugés négativement. Ses handicaps sont connus, qu'il s'agisse de l'illettrisme, du taux de chômage, de l'endettement ou du manque d'entreprises intermédiaires. Dans ce contexte, quelle pensée peut nous aider à mieux comprendre le présent et œuvrer pour l'avenir ? Une approche humaniste inspirée des travaux d'Alfred Sauvy ne serait-elle pas utile?

\section{Une méthode pour...}

Alfred Sauvy naît en 1898 dans les Pyrénées-Orientales. Après être devenu polytechnicien, il est nommé, en 1922, statisticien-adjoint à la Statistique générale de la France où il effectue d'abord le travail, ingrat mais essentiel, de collecte des informations statistiques. Il appartient à une génération d'ingénieurs-économistes marqués dans leur jeunesse par la France appauvrie de l'Entre-deux-guerres et ses réflexes malthusiens et déflationnistes. Aussi s'insère-t-il progressivement dans des réseaux où sont abordés les problèmes de l'expertise, de l'information économique et de la statistique. Selon lui, la bonne connaissance est celle qui est fondée sur l'observation des faits et leur analyse. Alfred Sauvy prend donc ses distances avec l'économie politique traditionnelle, écrivant par exemple que trop d' « économistes fabriquent des modèles qui seraient parfaits si l'homme n'existait pas ".

Sans délaisser l'économie, l'importance qu'il donne à l'action des hommes en faveur du bien commun le conduit à approfondir les questions démographiques, alors que la science de la population est encore, en 1945, " une science sauvage, sans maître ni élèves, cultivée seulement par des amateurs - dans le meilleur sens du terme - ou bien abordée occasionnellement sous l'un de ses aspects par des économistes, des statisticiens, des ethnographes ${ }^{1}$. Et Alfred Sauvy devient le maître de la démographie, ce que reconnaît le Collège de France en l'accueillant en 1959, avec une chaire intitulée «Démographie sociale ». C'est la première fois que cet intitulé entre dans cette prestigieuse institution française.

Témoin des prouesses de la médecine moderne, découvrant combien une approche scientifique objective permet de comprendre la réalité et d'éclairer la décision, il se fixe comme mission d'informer les hommes, ne supportant pas le nombre de décisions politiques reposant sur une ignorance à la fois « bien portée » et « plus poussée que celle des médecins de Molière $»^{2}$.

Il privilégie une méthode en quatre temps. Le premier est la phase de collecte des données. Le second est le diagnostic permettant d'identifier les problèmes. Le troisième temps consiste à établir des pronostics ou des perspectives conditionnelles pour nourrir la réflexion.

\section{..éclairer l’action}

Enfin, quatrième et dernier temps, le but final est d'éclairer l'action. L'expert-homme d'action n'est nullement un technocrate. D'une part, il considère que sa mission est d'informer les hommes politiques, quels qu'ils soient, avec des analyses fondées sur une exacte connaissance des faits. D'autre part, Alfred Sauvy entreprend une large œuvre de vulgarisation car il faut également donner des clés de lecture à tous les citoyens. Dans ce dessein, il publie de nombreux livres et donne de multiples chroniques dans les périodiques les plus divers : Le Nouvel Observateur, L'Expansion, Ouest-France, La Nouvelle République du Centre-Ouest, Géo..

Alfred Sauvy prend appui sur sa méthode et sur une approche pluridisciplinaire (économie, démographie, sociologie et histoire) de l'homme en collectivité pour pourchasser le malthusianisme sous toutes ses formes. Il démontre l'inanité des raisonnements simplistes relatifs aux relations supposées entre le progrès technique et le chômage, au problème des retraites, à l'immigration... Sa Théorie générale de la population est émaillée de commentaires quant aux erreurs manifestes qu'il décèle dans les comportements des hommes, des groupes sociaux et du personnel politique. En matière de retraite, il déplore à de nombreuses reprises, notamment dans les années 1970, l'inculture démographique de ses contemporains qui, négligeant les enseignements de l'étude attentive de la pyramide des âges, proposent des projets naiff : " On ne gagne pas une guerre économique en ne pensant qu'à adoucir le sort des citoyens et en se donnant pour objectif d'assurer à tout le monde une retraite paisible à un âge aussi bas que possible. » Plaçant le souci de l'emploi avant tout autre, son ouvrage La machine et le chômage (1980) lui permet de décrire les relations complexes entre progrès technique et emploi : l'origine du chômage tient surtout à l'ignorance des besoins encore à satisfaire, au malthusianisme économique, à la trop faible élasticité de l'offre compromise par des rigidités existantes ou introduites par des mesures dogmatiques néfastes, méconnaissant les faits.

L'intérêt de la méthode d'Alfred Sauvy est de nous aider à réfléchir aux enjeux du moment et aux réponses à leur apporter. Ces réponses ne peuvent faire l'économie de l'observation et de la mesure, dans un temps long, des phénomènes économiques, démographiques et sociaux, de leur comparaison et du croisement d'approches disciplinaires ${ }^{3}$.
1. Population, volume $1, n^{\circ} 1$ janvier-mars 1946. Texte no Jancer signé mais à l'évidence rédige par Alfred Sauwy, le créateur de cette revue.

2. Sauwy, Alfred, La vie en plus, Paris, Calmann-Lévy, 1981.

3. Avec pour objet «l létude, la diffusion ot la prolongation (ifusion et la prolongation de "euve dilfred Sauy ", un Association Alfred Sauvy vient de naître. Elle est joignable par correspondance « aux bons soins de Population \& Avenir, 35 Avenue Mac Mahon, 75017 Paris 04 percourie

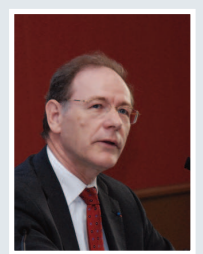

POPULATION \& AVENIR N $^{0} 708$. MAI-JUIN 2012 